\title{
Filling Lateral Canals: Evaluation of Different Filling Techniques
}

\author{
Bruno Carvalho-Sousa ${ }^{a}$ \\ Fábio Almeida-Gomes ${ }^{a}$ \\ Pollyana Rabelo Borba Carvalhob \\ Cláudio Maníglia-Ferreirac \\ Eduardo Diogo Gurgel-Filhoc \\ Diana Santana Albuquerque ${ }^{d}$
}

\begin{abstract}
Objectives: The purpose of this in vitro quantitative laboratorial study is to compare the ability of three filling techniques to fill simulated lateral canals.

Methods: Thirty extracted, single-rooted human teeth were used. After cleaning and shaping, three lateral canals were created, one in each third. The teeth were randomly separated into three groups: continuous wave of condensation (Group 1); thermomechanical compaction (Group 2); and lateral condensation (Group 3). The teeth were cross-sectioned, making the cut through points over the lateral canals; thus, 90 specimens were obtained. Each specimen was immersed in a polyester resin, and the blocks were polished. Images were obtained using a stereoscopic lens (40x). Radiographic analysis was performed, followed by a filling linear measure using the Image Tool 3.0 program (University of Texas). Data were statistically analyzed using SPSS 12.0 for Windows (KruskalWallis test).

Results: A greater number of simulated lateral canals were obturated in Groups 1 and 2. Group 2 presented the largest percentage of linear measure of lateral canals filling with gutta-percha and sealer. No statistical differences were found between Group 1 and Group 2 when we analyzed the filling with gutta-percha and sealer or just sealer $(P>.05)$.

Conclusions: Thermoplasticized gutta-percha filling techniques (Groups 1 and 2) are better for filling lateral canal with gutta-percha and sealer or with just sealer than lateral condensation (Group 3). (Eur J Dent 2010;4:251-256)
\end{abstract}

Key words: Endodontics; Root canal obturation; Root canal filling materials.

a MsD, PhD Program, University of Pernambuco, Brazil.

b Graduate student, Master Program, University of Pernambuco, Brazil.

PhD, Adjunct professor, Department of Endodontics, University of Fortaleza, Brazil.

d PhD, Adjunct professor, Department of Endodontics, University of Pernambuco, Brazil,

- Corresponding author: Bruno Carvalho-Sousa 95 Paulo Faustino Street, Luciano Cavalcante, 60813-530, Fortaleza, Ceará, Brazil.

Phone: (85) 32787337

E-mail: brunendolahotmail.com

\section{INTRODUCTION}

Studies found lateral canals in $45 \%$ of 74 teeth $^{1}$ and $27.4 \%$ of 1140 teeth observed. ${ }^{2}$ Lateral canals are difficult to instrument and to irrigate during endodontic therapy and may allow bacterial growth. ${ }^{1}$ Although some authors found no correlation between unfilled lateral canals and inflammation of the periodontal ligament, ${ }^{3}$ other studies demonstrated their potential pathogenicity after healing of periradicular lesions in relation with full filling of lateral canals. ${ }^{4-6}$ 
Persisting bacteria in teeth endodontically treated $^{7}$ may be located in uninstrumented areas like lateral canals. ${ }^{6}$ In this case, the threedimensional obturation of the root canal system becomes extremely important, as it could prevent reinfection ${ }^{8}$ and isolate microorganisms in inaccessible areas, without access to space and nutrients. ${ }^{9,10}$

The capability of an endodontic filling technique to ensure the filling of thin and irregular ramifications is an important clinical parameter and may represent a favorable aspect of the filling technique. Different techniques have been proposed over the years, and several in vitro models have been proposed to compare the results of these filling techniques. For this purpose, artificial lateral canals were created using various methods. Considering the high number of in vitro techniques proposed over the years, a model with a main and various lateral canals would be an important tool with which to investigate and compare filling techniques. ${ }^{11}$

The purpose of this study is to compare the ability of three filling techniques to fill simulated lateral canals (Continuous Wave of Condensation, Thermomechanical Compaction, and Lateral Condensation) and, also, compare the percentage of lateral canals filled by gutta-percha and sealer.

\section{MATERIALS AND METHODS}

Thirty extracted human single-rooted teeth were used for this study. All teeth presented extracted indications of advanced periodontal disease. A single operator carried out all steps. Conventional endodontic access was prepared using round diamond drill (KG Sorensen, São Paulo, Brazil). The canal length was visually established by placing a size $10 \mathrm{~K}$-file in each root canal until it was seen emerging through the apical foramen. The working length was established at $1 \mathrm{~mm}$ short of the apex. The coronal and middle thirds of each canal were flared using 4, 3, 2, Gates Glidden drills (Dentsply Maillefer, Ballaigues, Switzerland). All teeth were instrumented to the working length of a size $40 \mathrm{~K}$-file. A step-back preparation with sizes 45,50 , and $55 \mathrm{~K}$-file was performed. After each instrument, the canals were irrigated with $3 \mathrm{ml}$ of $2.5 \%$ sodium hypochlorite solution (Biodinâmica Química, Ibiporã, Paraná, Brazil) using a 27-gauge needle (Hypodermic, Shanghai, China) that pen- etrated to the middle third.

The smear layer of the root canals was removed using irrigation with $10 \mathrm{ml}$ of EDTA $17 \%$ (Biodinâmica Química, Ibiporã, Paraná, Brazill through manual activation with a $40 \mathrm{~K}$-file for 3 minutes for each canal, followed by a $5 \mathrm{ml}$ flush with sodium hypochlorite. After that, canal patency was verified using a size $20 \mathrm{~K}$-file and dried by paper points (Dentsply Maillefer, Ballaigues, Switzerland).

Three simulated lateral canals were then drilled on the mesial surfaces of the root lone in each third), perpendicular to the main canal at 3 $\mathrm{mm}, 6 \mathrm{~mm}$, and $9 \mathrm{~mm}$ from the apex, using a \#15 engine reamer $(H$. Shein, New York, NY). The lateral canals showed a slightly tapered shape, with the base side to the external root surface (Figure $1 \mathrm{Al}$.

Teeth were randomly separated into three groups of 10 specimens. For all groups, Grossman sealer (Endofill, Dentsply Maillefer, Petrópolis, RJ, Brazil) was used as the root canal sealer. The sealer was mixed according to the manufacturer's instructions and applied by coating the canal walls using the main cone itself. Afterward, the root canals were filled (Figure 1B) according to following techniques.

Group 1 (Continuous wave of condensation)

A medium gutta-percha cone 0.06 (Konne Ind. Com. Ltda, Belo Horizonte, Brazil) was fitted to working length using a calibrator rule (Dentsply Maillefer, Petrópolis, RJ, Brazil) that adjusts the tip of the cone to the size $40 \mathrm{~K}$-file. The heat source was activated, and a preheated medium plugger (System B, Analytic Technology, Glendora, CA, USA) was inserted into the root canal to thermoplasticize and compact the gutta-percha at the apical third, $5 \mathrm{~mm}$ from the apex. Vertical compaction was performed using a size 2 plugger (JR instrumental LTDA, Belo Horizonte, Brazil). The middle and coronal thirds of root canal were backfilled using Obtura II (Obtura Corporation, Penton, Missouri, USA).

\section{Group 2 (Thermomechanical technique)}

A medium gutta-percha cone 0.06 was adjusted in the same manner as in the previous group. Lateral condensation was performed using a size C finger spreader (Dentsply Maillefer Ballaigues, Switzerland) and fine accessory gutta- 
percha cones. The gutta-percha excess was removed using a heat plugger, and the gutta-percha mass was thermomechanically compacted at the coronal and middle thirds of the root canals using a size 45 gutta-condensor (Dentsply Maillefer, Ballaigues, Switzerland) rotated at $\sim 10.000$ rpm in a slow handpiece for 10 seconds. ${ }^{12}$ Finally, the gutta-percha was compacted vertically using Schilder's pluggers (JR instrumental LTDA, Belo Horizonte, Brazil).

\section{Group 3 (Lateral condensation)}

A medium gutta-percha cone 0.06 was adjusted in the same manner as in the previous group. Lateral condensation was performed using a size $C$ finger spreader and fine accessory gutta-percha cones. The gutta-percha excess was removed using heated Schilder's pluggers, and, finally, the gutta-percha was compacted vertically using Schilder's pluggers.

Immediately after filling, postoperative radiographs were taken in the buccolingual direction, and all of them were identically exposed, developed, and fixed. The teeth were cross-sectioned using an isomet precision saw (Buhler Ltd., Lake Bluff, NY, USA) and a diamond disc ( $\emptyset 125 \mathrm{~mm}$ $\times 0.35 \mathrm{~mm} \times 12.7 \mathrm{~mm}-330 \mathrm{C}$ ) at the low speed, placed perpendicular to the main canal at $4 \mathrm{~mm}$, $7 \mathrm{~mm}$, and $10 \mathrm{~mm}$ from the apex $(1 \mathrm{~mm}$ above the point of making the lateral canals). Thus, 90 specimens were obtained (Figure $1 \mathrm{C}$ ). During this procedure, the specimens were constantly irrigated with water to prevent overheating.

After cross-sectioning, each specimen was immersed in a polyester resin (Cebtrofibra, Fortaleza, Brazil) to make their manipulation simpler (Figure 1D). The blocks were polished using specific sandpaper (DP-NETOT 4050014-Struers, Ballerup, Denmarkl for materialographic preparation. The specimens were polished prior to their examination under the stereoscopic lens using a diamond paste of 4-1 $\mu \mathrm{m}$ roughness (SAPUQ 40600235, Struers) and sandpaper size 1000. This was done to avoid gutta-percha deformation and to obtain a surface that was free from scratches and deformities, resulting in a highly reflective surface. ${ }^{13}$

Images were obtained (Figures 2 and 3) using a Nikon Coolpix E4.300 pixel digital camera (Nikon Corp. Korea) connected to a stereoscopic lens (Lambda Let, Hong Kong, China) (40x). Radiographic analysis and a filling linear measure (Figure 4) using the Image Tool 3.0 program (University of Texas) were performed. For the radiographic analysis, a lateral canal qualified as filled when it appeared to be filled to the external surface of the root.

Data were statistically analyzed using SPSS 12.0 for Windows (SPSS Inc., Chicago, IIL, USA), and this software indicated the Kruskal-Wallis test (nonparametric test, samples not normal) to test the null hypothesis that there was no relationship between filling technique and the filling ability of the simulated lateral canals with gutta-percha.

\section{RESULTS}

The teeth in Group 1 (Continuous wave of condensation) had the largest number of filled lateral canals in the radiographic analysis, followed by Group 2 (Thermomechanical technique) and Group 3 (Lateral condensation) (Table 1). Groups 1 and 2 were statistically different from Group $3(P<.01)$.

The coronal third had a larger number of filled lateral canals than the middle and apical thirds, in the radiographic analysis (Table 2). Differences between the root thirds were not statistically significant ( $P>$.05).

Group 2 had the largest linear measure percentage of simulated lateral canals filled with gutta-percha and sealer $(P<.05)$. No statistical differences were found between Group 1 and Group 2 when we analyzed the filling with gutta-percha and sealer or just sealer ( $P>$.05). No statistical differences were found between Group 1 and Group 3 when we analyzed the filling with just sealer (P>.05) (Table 3).

The Image Tool 3.0 program was used to obtain the linear measure. Groups 1 and 2 had the largest linear measure percentage of lateral canals filled (gutta-percha and sealer) and were statistically different from Group $3(P<.01)$.

\section{DISCUSSION}

The ramifications in the main canal, such as lateral canals, have great clinical importance in endodontic therapy, mainly when associated with lateral lesions. The vertical condensation of the warm gutta-percha technique produces consistently dense, dimensionally stable, three-dimensional root canal fillings. Lateral canals are filled 
with extraordinary frequency, often with guttapercha and sometimes with sealer. ${ }^{14}$

The aim of root canal treatment is to fill the root canal system and isolate microorganisms in inaccessible areas, without access to space and nutrients. Thus, we reestablish the normal condition of the periapical tissue. ${ }^{15}$ The use of sealers which have good flow rates, among other requisites, and

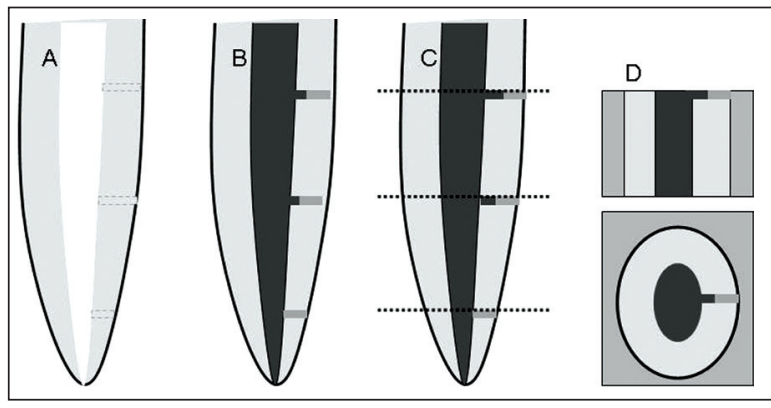

Figure 1. Scheme showing the simulated lateral canals on the mesial surfaces of the root (A); after filling (B); cross-section - lateral vision 3 parts (C); and crosssection after immersion in polyester resin - lateral and transversal visions (D).

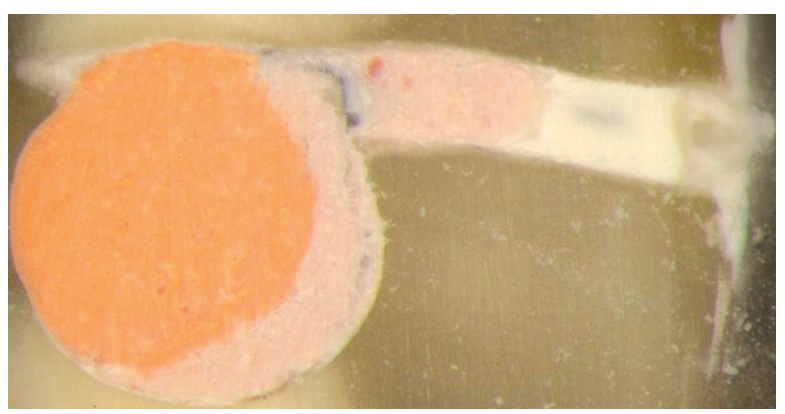

Figure 2. Cross-section showing simulated lateral canal filled with gutta-percha and sealer (Group 2 - medium third). whose composition is based on inert materials, is necessary. ${ }^{16,17}$

There are several studies dealing with lateral canals. Some of them employed epoxy resin blocks; ${ }^{11,18,19}$ others simulated lateral canals in natural human teeth. ${ }^{16,20,21}$ The authors are aware of the limitations of using epoxy blocks versus natural teeth. The surface texture and resin conditions could positively or negatively influence the flow properties of the gutta-percha or sealer. Dentin is an excellent thermal insulator, whereas this property in acrylic substrates is unknown. However, the use of resin allowed us to create an ideal canal shape for filling and the standardized lateral canal. 11,19,22

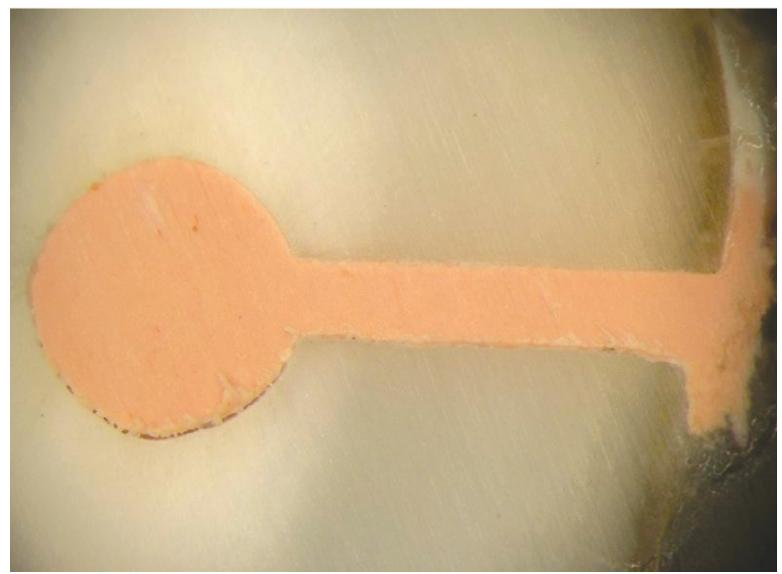

Figure 3. Cross-section showing simulated lateral canal filled with gutta-percha (Group 1 - coronal third).

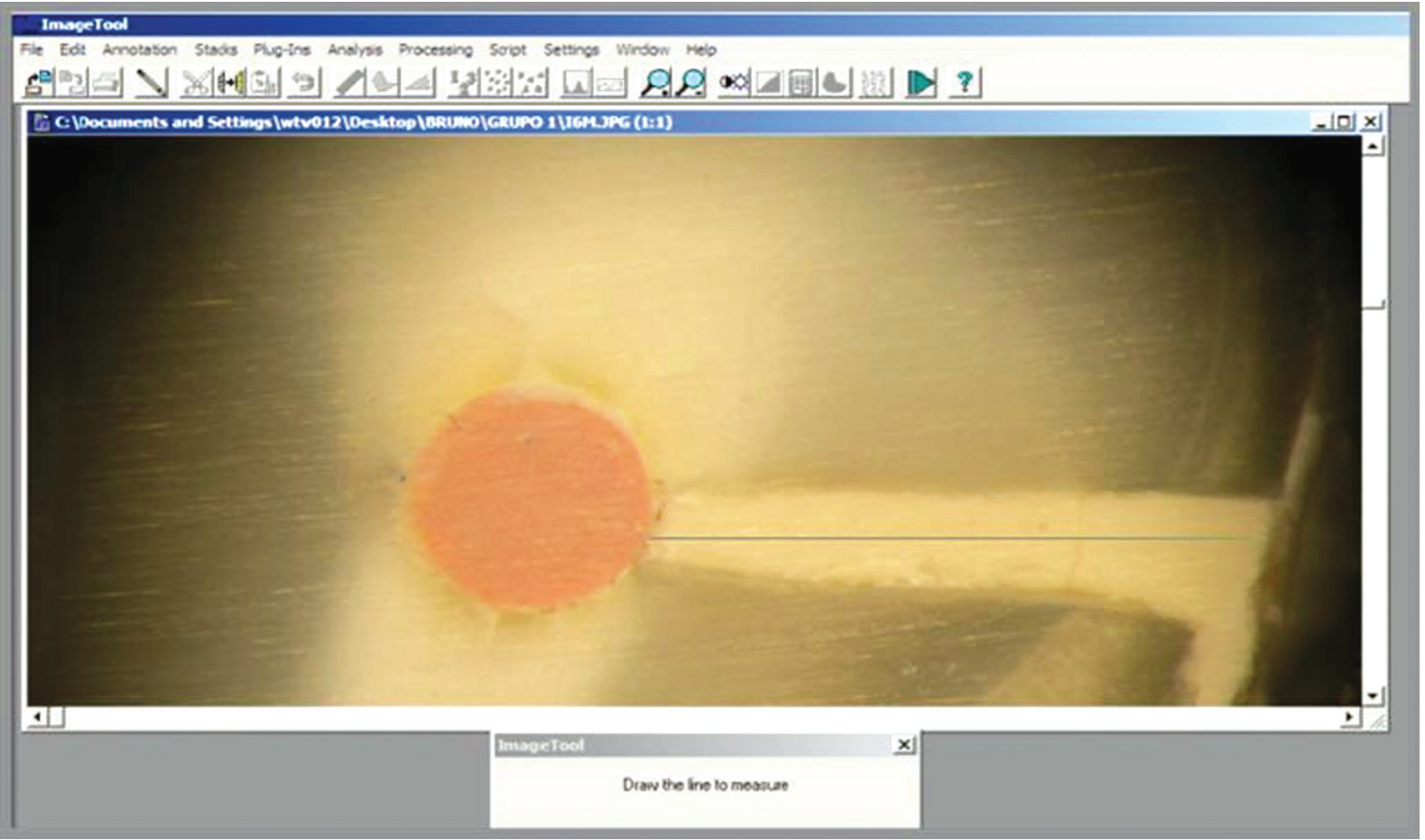

Figure 4. Linear obturation measurements performed using the Image Tool 3.0 software (University of Texas Health Science Center, CA, San Antonio, USA). (Group 3 - medium third). 
In this study, to reproduce the conditions observed in clinical practice, simulated lateral canals were created having a diameter of approximately $\sim 150 \mu \mathrm{m}$, which is in accordance with the size of lateral canals reported in previous studies. ${ }^{23,24}$ The lateral canals showed a slightly tapered shape, with a base side to the external root surface. However, the taper does not improve the flow of filling material, because the base of the taper is on the root external surface.

X-ray analysis, ${ }^{20,21}$ one-dimensional observation in epoxy blocks, ${ }^{11}$ and tooth-clearing techniques $^{22}$ were used to evaluate the lateral canal fillings. The filling quality of each lateral canal could be better analyzed by cross-sectional comparison within and between each technique. ${ }^{11}$ In this present study, a cross-section of the root canals was cut through points over the lateral canals. After the specimens were set in epoxy resin and the resin polished, photos were taken at 40X magnification, and the images permitted us to view the presence or absence of gutta-percha and sealer in each lateral canal. In this way, other kinds of analyses could be performed.

Several studies have reported endodontic success after filling of lateral canals and different filling techniques were proposed to achieve better obturation of these canals. ${ }^{11,14}$ Although some studies cast doubt on the idea that the type of canal filling technique has a great effect on the number of lateral canals filled, ${ }^{9,20}$ other studies have demonstrated that vertical compaction of warm gutta-percha increases the capacity of lateral canal filling. ${ }^{14,21}$

Table 1. Simulated lateral canals filled according to each technique ranked in decre-

\begin{tabular}{lccc}
\hline & \multicolumn{2}{c}{ X-ray analysis } \\
\hline Groups & Canals & Filled & Unfilled \\
\hline 1 & 30 & $30^{*}$ & - \\
2 & 30 & $29 *$ & 1 \\
3 & 30 & $23^{* *}$ & 7 \\
\hline
\end{tabular}
asing order. X-ray analysis.

Thermoplasticized techniques and cold techniques were compared in 360 simulated lateral canals. According to the results given by X-ray analysis, the thermoplasticized techniques filled more lateral canals. ${ }^{20}$ In particular, the thermoplasticized techniques allow the high compaction forces to be directed towards the gutta-percha within the accessory canals, resulting in a complete three-dimensional filling of ramifications of the middle and coronal regions. ${ }^{22}$

In this present study, the thermoplasticized techniques, either heat source or mechanical, filled more lateral canals than the lateral condensation technique, and the apical third was less filled than the other thirds. Groups 1 and 2 had $91.26 \%$ and $95.93 \%$ of the extension of lateral canals filled with gutta-percha and sealer, respectively. Group 2 had more gutta-percha in the lateral canals than did the other two groups. This fact may have been caused by the lateral force of the gutta-condenser rotation.

The literature have reported that the warm gutta-percha technique promotes better filling quality and results in virtually no gaps, very low amounts of sealer on the root surface, and greater adaptation to dentinal walls, unlike the lateral condensation technique. ${ }^{15}$

In this study, when thermoplasticized guttapercha techniques were used, a greater frequency of filled lateral canals was noted compared with lateral compaction of gutta-percha. Thermoplasticized gutta-percha techniques were better than lateral condensation technique to fill simulated lateral canals.

Table 2. Simulated lateral canals filled in each root third. X-ray analysis.

\begin{tabular}{lccc}
\hline & \multicolumn{2}{c}{ X-ray analysis } \\
\hline Thirds & Canals & Filled & Unfilled \\
\hline Coronal & 30 & 29 & 1 \\
Middle & 30 & 27 & 3 \\
Apical & 30 & 26 & 4
\end{tabular}

Table 3. Percentage of linear mensuration of filling material present in simulated lateral canals.

\begin{tabular}{lccc}
\hline Groups & Gutta-percha + Sealer & Sealer & Voids \\
\hline 1 & $25.05 \% *$ & $66.21 \% *$ & $8.73 \% *$ \\
2 & $62.70 \% * *$ & $33.23 \% * *$ & $4.07 \% *$ \\
3 & $1.79 \% * * *$ & $66.52 \% *$ & $31.69 \% * *$ \\
\hline
\end{tabular}

Different symbols show a statistic significant difference between groups. 


\section{CONCLUSIONS}

Thermoplasticized gutta-percha filling techniques are better for filling lateral canal with gutta-percha and sealer or with just sealer than lateral condensation. However, the present study was performed in vitro, and it is not possible to establish a direct correlation with clinical findings.

Moreover, it should be noted that, although the results suggest the superiority of one technique over another, there is no scientific evidence proven through clinical studies.

\section{REFERENCES}

1. Rubach WC, Mitchell DF. Periodontal disease, accessory canals and pulp pathosis. J Periodontol 1965;36:34-38.

2. De Deus QD. Frequency, location and direction of the lateral, secondary and accessory canal. J Endod 1975;1:361366.

3. Barthel CR, Zimmer S, Trope M. Relationship of radiologic and histologic signs of inflammation in human root-filled teeth. $J$ Endod 2004;30:75-79.

4. Seltzer S, Bender IB, Ziontz M. The interrelationship of pulp and periodontal disease. Oral Surg Oral Med Oral Pathol 1963;16:1474-1490.

5. Seltzer S, Bender IB, Smith J, Freedman I, Nazimov H. Endodontic failures-an analysis based on clinical, roentgenographic, and histologic findings. Oral Surg Oral Med Oral Pathol 1967;23:500-516.

6. Weine FS. The enigma of the lateral canal. Dent Clin North Am 1984;28:833-852.

7. Fukushima H, Yamamoto K, Sagawa H, Leung KP, Walker $\mathrm{CB}$. Localization and identification of root canal bacteria in clinically asymptomatic periapical pathosis. $J$ Endod 1990;11:534-538

8. Pinheiro ET, Gomes BPFA, Ferraz CCR, Sousa ELR, Teixeira FB, Souza-Filho FJ. Microorganisms from canals of root-filled teeth with periapical lesions. Int Endod $J$ 2003;36:1-11.

9. Nichols E. Lateral radicular disease due to lateral branching of the root canal. Oral Surg Oral Med Oral Pathol $1963 ; 16: 839-845$.

10. Vivacqua-Gomes N, Gurgel-Filho ED, Gomes BP, Ferraz CC, Zaia AA, Souza-Filho FJ. Recovery of Enterococcus faecalis after single or multiple-visit root canal treatment carried out in infected teeth ex vivo. Int Endod J 2005;38:697-704.

11. Dulac KA, Nielsen CJ, Tomazic TJ, Ferrillo PJ, Hatton JF. Comparison of the obturation of lateral canals by six techniques. J Endod 1999;25:376-380.
12. Tagger M. Use of thermo-mechanical compactors as an adjunct to lateral condensation. Quintessence Int 1984;15:2730.

13. De Deus GA, Gurgel-Filho ED, Maníglia-Ferreira C, Coutinho Filho $T$. The influence of filling technique on depth of tubule penetration by root canal sealer: a study using light microscopy and digital image processing. Aus Endod $J$ 2004;30:23-28.

14. Schilder H. Filling root canal in three dimensions. Dent Clin North Am 1967;11:723-744.

15. Guigand M, Glez D, Sibayan E, Cathelineau G, Vulcain J-M. Comparative study of two canal obturation techniques by image analysis and EDS microanalysis. Br Dent $J$ 2005;198:707-711.

16. Pécora JD, Ribeiro RG, Guerisol DMZ, Barbizam JVB, Marsesam MA. Influence of the spatulation of two zinc oxide and eugenol based sealers on the obturation of lateral canals. Braz Oral Res 2002;16:127-130.

17. De Deus GA, Gurgel-Filho ED, Maníglia-Ferreira C, Coutinho-Filho T. Penetração intradentinária de quatro cimentos endodônticos. Braz Oral Res 2002;16,332-336.

18. Bowman CJ, Baumagartner JC. Gutta-percha obturation of lateral groves and depressions. J Endod 2002;28:220-223.

19. Reader CM, Himel VT, Germain LP, Hoen MM. Effect of three obturation techniques on the main canal. $J$ Endod 1993;19:404-408.

20. Goldberg F, Artaza LP, Sílvio A. Effectiveness of different obturation techniques in the filling of simulated lateral canals. J Endod 2001;27:362-364.

21. Goldberg F, Artaza LP, Sílvio A. Influence of calcium hydroxide dressing on the obturation of simulated lateral canals. $J$ Endod 2002;28:99-101.

22. Venturi M, Prati C, Capelli G, Falconi M, Breshi L. A preliminary analysis of the morphology of lateral canals after root canal filling using a tooth-clearing technique. Int Endod J 2003;36:54-63.

23. Perlich MA, Reader A, Foreman DW. A scanning electron microscopic investigation of accessory foramens on the pulpar floor of human molars. J Endod 1981;7:402-406.

24. Vertucci FJ, Anthony RL. A scanning electron microscopic investigation of accessory foramens in the furcation and pulp chamber floor of molar teeth. Oral Surg Oral Med Oral Pathol 1986;62:319-326. 